\title{
Cardiac magnetic resonance imaging predictors of atrial arrhythmias in patients with repaired tetralogy of Fallot
}

Anne Marie Valente ${ }^{1 *}$, Shelby Kutty ${ }^{2}$, Matthew White ${ }^{1}$, Jenna Schreier ${ }^{1}$, Jouke Bokma ${ }^{1}$, Edward P Walsh', Michael J Landzberg ${ }^{1}$, Andrew J Powell', Tal Geva ${ }^{1}$

From 18th Annual SCMR Scientific Sessions

Nice, France. 4-7 February 2015

\section{Background}

Patients with repaired tetralogy of Fallot (TOF) experience increased rates of atrial tachyarrhythmias in adulthood. Our objective was to identify cardiac magnetic resonance (CMR) imaging parameters associated with sustained atrial arrhythmias in a large contemporary cohort of patients with repaired TOF.

\section{Methods}

Subjects with repaired TOF with a CMR performed at our institution between 2005-2012 and with clinical follow-up $\geq 1$ year or with occurrence of the primary outcome were included. The primary outcome was defined as sustained atrial tachycardia (atrial flutter, atrial fibrillation, or supraventricular tachycardia undergoing arrhythmia-directed therapy), occurring after the index CMR.

\section{Results}

The cohort includes 365 subjects (median age 18.6 years), and consisted of TOF/ pulmonary stenosis (74\%), TOF/pulmonary atresia (23\%), and TOF/atrioventricular canal (3\%). Over $50 \%$ of the subjects had undergone a

Table 1 Predictors of Atrial Arrhythmias in Patients with Repaired TOF

\begin{tabular}{|c|c|c|c|c|c|}
\hline CMR Variables & & $\mathrm{HR}$ & $95 \% \mathrm{Cl}$ & $p$ value & C Index \\
\hline Max RA volume index $\left(\mathrm{mL} / \mathrm{m}^{2}\right)$ & $\uparrow 5$ & 1.10 & $(1.04,1.17)$ & 0.002 & 0.604 \\
\hline Min RA volume index $\left(\mathrm{mL} / \mathrm{m}^{2}\right)$ & $\uparrow 5$ & 1.13 & $(1.06,1.21)$ & $<0.001$ & 0.619 \\
\hline RA FAC (\%) & $\downarrow 10$ & 1.86 & $(1.14,3.03)$ & 0.013 & 0.615 \\
\hline RA ejection fraction (\%) & $\downarrow 10$ & 1.37 & $(1.01,1.88)$ & 0.046 & 0.596 \\
\hline RV diastolic volume z-score & $\uparrow 3$ & 1.42 & $(1.04,1.94)$ & 0.029 & 0.585 \\
\hline RV systolic volume z-score & $\uparrow 3$ & 1.25 & $(1.06,1.48)$ & 0.007 & 0.564 \\
\hline RV ejection fraction (\%) & $\downarrow 10$ & 1.29 & $(0.88,1.89)$ & 0.19 & 0.446 \\
\hline RV mass z-score & $\uparrow 3$ & 1.31 & $(0.84,2.04)$ & 0.24 & 0.474 \\
\hline Tricuspid regurgitation (\%) & $\uparrow 5$ & 1.11 & $(0.86,1.44)$ & 0.43 & 0.517 \\
\hline Pulmonary regurgitation (\%) & $\downarrow 5$ & 1.14 & $(1.01,1.28)$ & 0.03 & 0.612 \\
\hline LV diastolic volume z-score & $\uparrow 3$ & 1.54 & $(0.96,2.48)$ & 0.07 & 0.621 \\
\hline LV systolic volume z-score & $\uparrow 3$ & 1.21 & $(0.9,1.65)$ & 0.21 & 0.593 \\
\hline LV ejection fraction (\%) & $\downarrow 10$ & 1.16 & $(0.71,1.89)$ & 0.56 & 0.510 \\
\hline LV mass z-score & $\uparrow 3$ & 1.45 & $(0.97,2.16)$ & 0.07 & 0.581 \\
\hline
\end{tabular}

$F A C$, fractional area change; $H R$, hazard ratio; $L V$, left ventricle; $R A$, right atrial; $R V$, right ventricle

${ }^{1}$ Cardiology, Boston Children's Hospital, Boston, MA, USA

Full list of author information is available at the end of the article

(c) 2015 Valente et al; licensee BioMed Central Ltd. This is an Open Access article distributed under the terms of the Creative Commons Attribution License (http://creativecommons.org/licenses/by/4.0), which permits unrestricted use, distribution, and reproduction in any medium, provided the original work is properly cited. The Creative Commons Public Domain Dedication waiver (http:// creativecommons.org/publicdomain/zero/1.0/) applies to the data made available in this article, unless otherwise stated. 
transannular patch repair and $23 \%$ had undergone a palliative shunt procedure prior to complete repair. Median age of repair was 0.6 years $(0.01-45.3$ years). Of the 365 subjects, $23(6 \%)$ reached the primary outcome (median age at outcome 30.7 years; median time from CMR to outcome 2.2 years). Univariate Cox proportional hazard regression models identified lower right atrial (RA) fractional area change (for a decrease of $10 \%, \mathrm{HR}=1.86$; $95 \%$ CI 1.14-3.03; $\mathrm{p}=0.013$ ), maximal RA volume index (for an increase of $5 \mathrm{ml} / \mathrm{m}^{2}, \mathrm{HR}=1.10 ; 95 \% \mathrm{CI}, 1.04-1.17 ; \mathrm{P}=0.002$ ), larger right ventricular (RV) end-diastolic volume (for a 3 standard deviation increase, $\mathrm{HR}=1.42 ; 95 \% \mathrm{CI}, 1.04-1.94$; $\mathrm{P}=0.029$ ), and less pulmonary regurgitation (PR) (for a $5 \%$ decrease, $\mathrm{HR}=1.14 ; 95 \% \mathrm{CI}, 1.01-1.28 ; \mathrm{p}=0.03$ ) as outcome predictors (Table 1). The degree of tricuspid regurgitation was not associated with the outcome.

\section{Conclusions}

Larger RA and RV size and lower RA function are predictive of atrial tachyarrhythmias in adults with repaired TOF. Given these findings, as well as a lower degree of PR in patients with atrial tachyarrhythmias suggests that a decrease in RV compliance may play a role in the outcome.

\section{Funding}

Higgins Family Noninvasive Research Fund at Boston Children's Hospital; The Lerner Research Award at Brigham and Women's Hospital.

\section{Authors' details}

${ }^{1}$ Cardiology, Boston Children's Hospital, Boston, MA, USA. ${ }^{2}$ Cardiology,

Children's Hospital \& Medical Center, Omaha, NE, USA.

Published: 3 February 2015
doi:10.1186/1532-429X-17-S1-Q102

Cite this article as: Valente et al:: Cardiac magnetic resonance imaging predictors of atrial arrhythmias in patients with repaired tetralogy of

Fallot. Journal of Cardiovascular Magnetic Resonance 2015 17(Suppl 1):

Q102.
Submit your next manuscript to BioMed Central and take full advantage of:

- Convenient online submission

- Thorough peer review

- No space constraints or color figure charges

- Immediate publication on acceptance

- Inclusion in PubMed, CAS, Scopus and Google Scholar

- Research which is freely available for redistribution

Submit your manuscript at www.biomedcentral.com/submit 